\section{JOURNAL OF THE SOUTH AFRICAN} INSTITUTION OF CIVIL ENGINEERING

Vol 58 No 2, June 2016, Pages 14-24, Paper 1232

\title{
Shortcomings in the estimation of clay fraction by hydrometer
}

\author{
P Stott, E Theron
}

The estimation of clay fraction is important for predicting the engineering properties of a soil. SANS 3001 GR3 (SANS 2011) specifies a procedure for clay fraction determination using a hydrometer. It has long been suspected that there may be flaws in this approach. Some of the possible sources of error have been suggested, but little or no change has been made in the standard procedures for assessment of clay fraction in well over half a century. This paper deals with a microscopic examination of some typical South African clayey soils to assess the adequacy of dispersion and possible consequences for clay fraction determination in currently specified hydrometer procedures. Clays are examined both with and without dispersant, and with and without labelling of clay minerals using an exchangeable cation dye.

\section{INTRODUCTION}

An estimation of the clay fraction of a soil is required for a number of soil evaluations, including common methods of assessing heave potential relating to foundation design. Van der Merwe's method (Van der Merwe 1964) uses the plasticity index (PI) and clay fraction. Skempton's "activity" is defined as PI/clay fraction (Skempton 1953). The method of estimating clay fraction by hydrometer, as specified in the South African standard SANS 3001 GR3 (SANS 2011), is very similar to that specified in Britain, America, Australia and many other countries. It is, however, somewhat dubious in its efficiency. Savage suggested that the hydrometer method may be doubtful due to four factors (Savage 2007):

1. Stoke's law assumes all particles to be spherical, while clays are flaky.

2. De-flocculation of many clays is seldom fully completed at the time of testing.

3. Clay particles are partially carried down by the larger particles.

4. A relative density of 2.65 is assumed for all particles, which may not be true.

Savage proposed a method of estimating clay fraction indirectly by using Skempton's activity formula. Unfortunately there seems to be no clear pattern of correlation between hydrometer results and Savage's method. Savage did not give examples, and the examination of samples by the Central University of Technology (CUT) Soil Mechanics Research Group revealed no clear pattern of correlation (some values higher, some lower than the hydrometer). There appears to be no way of telling which gives the better estimate, or what the likely margins of error may be. The method does not appear to have found wide acceptance.
Progress has been made on Savage's first point, the question of non-sphericity of particles. It has been addressed by laser scattering techniques for particle suspensions (e.g. Konert \& Vandenberghe 1997; McCave et al 1986; Ma et al 2000). This technique has enabled an allowance to be made for particle shape, and has generally led to a small but significant increase in clay fraction estimation. Such an allowance is not specified in SANS 3001 GR3.

Savage's fourth point seems to have drawn little attention, since almost all non-organic soil components have densities reasonably close to 2.7 , and the likely error due to this factor is probably quite small. His remaining two points concern dispersion, and obviously merit attention.

Research currently being done on the theoretical aspects of dispersion of clay particles suggests that the problem is far from well understood (e.g. Robinet et al 2011), and it remains very difficult to assess most aspects of dispersion for any specific clay and solute system. Experimental research on de-flocculation/dispersion using nontraditional de-flocculants currently appears to be concentrated on ceramics (e.g. Al-Lami 2008). Such dispersants produce functional groups acting as spacers between clay particles and may be too expensive for routine soils testing at this stage of development. Work on de-flocculation/dispersion relevant to soil mechanics continues to use methods and dispersants which have been in use for many years (e.g. Rodriguez et al 2011; Rolfe et al 1960). Attempts to assess the magnitude of error likely to be involved in incomplete dispersion continue to use the hydrometer itself as the instrument of investigation 
(Nettleship et al 1997; Rodriguez et al 2011). This paper is primarily concerned with Savage's second point, the dispersion of clay particles. His third point, clay being carried down with larger particles, follows from this as a matter of course.

\section{THEORETICAL BACKGROUND TO DISPERSION OF CLAYS}

The behaviour of dispersants is complex and appears to be still imperfectly understood.

This outline synthesises information from Das (2008), Zschimmer and Schwartz (2014), Nettleship et al (1997) and Robinet et al (2011).

Clay particles carry charges which leave their inner structure negatively charged and tend to leave their outer edges positively charged. When active clay soils are mixed with water, two things tend to happen.

Firstly, water molecules, which are polar (their atomic structure leaves one side positively charged and the other side negatively charged, while remaining neutral as a whole), surround cations (positively charged metal ions) in the soil. When coated with water the cations become mobile. They are strongly attracted by the negative charges in the interior of some types of clay minerals and penetrate between the tetrahedral and octahedral sheets of these clays, forcing the sheets apart. This is the reason why some clays can increase in volume powerfully when wetted. Secondly, the positively charged outer edges of the clay particles attract negatively charged ions which form a diffuse layer whose concentration diminishes with distance from the clay surface. Multi-valent ions provide multiple electro-negativity and relatively few of them need to congregate around a clay particle to balance the positive charge on the surface of the clay. The resulting field surrounding the clay has marked peaks at the ions and troughs between them. This allows adjacent clay particles to maintain mutual electrical attraction by fitting troughs on one particle to peaks on another.

In order to assess clays by their rate of precipitation, as in the pipette and hydrometer methods, it is necessary to disperse the particles of clay into the water through which they precipitate. Mechanical agitation is essential for this, but is not sufficient on its own. Chemical dispersion is needed to break the bonds of electrical attraction holding assemblages of clay particles together.

Dispersants work in three ways. The first is to replace multi-valent ions at the clay surface by mono-valent ions. When an individual clay particle is surrounded by sufficient mono-valent ions to render it electro-neutral, the field surrounding it is relatively uniform; clay particles in such a

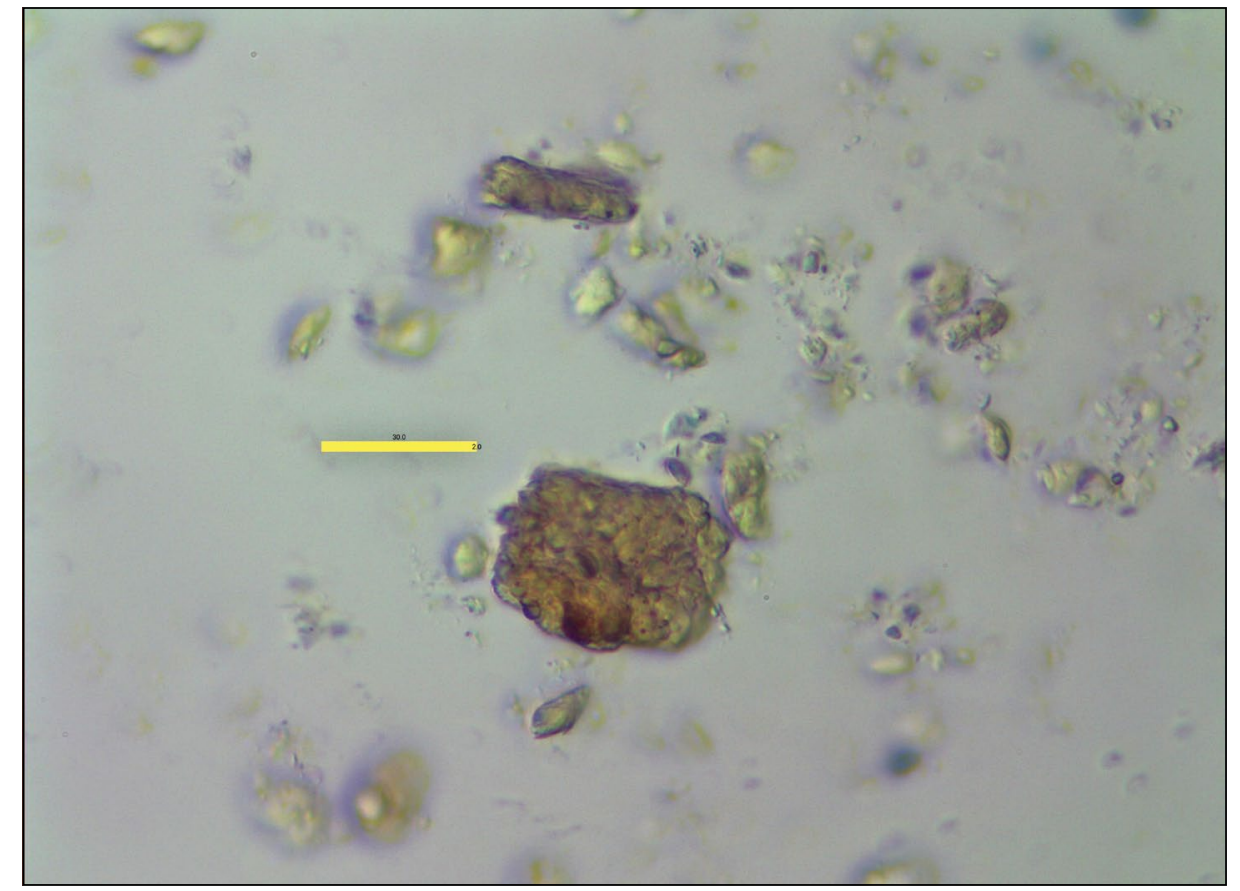

Photograph 1 Olive-grey residual clay not treated with dispersant but mechanically stirred as specified in SANS $3001 \mathrm{GR3}$

Comparison with the 30 micron by 2 micron rectangle suggests that there are particles of about 2 microns attached to several of the silt particles. Some clay-size particles appear to be dispersed in suspension. Note the faint pinkish cloudy patches covering a considerable part of the field of view (most of which is not within the lens's range of sharp focus).

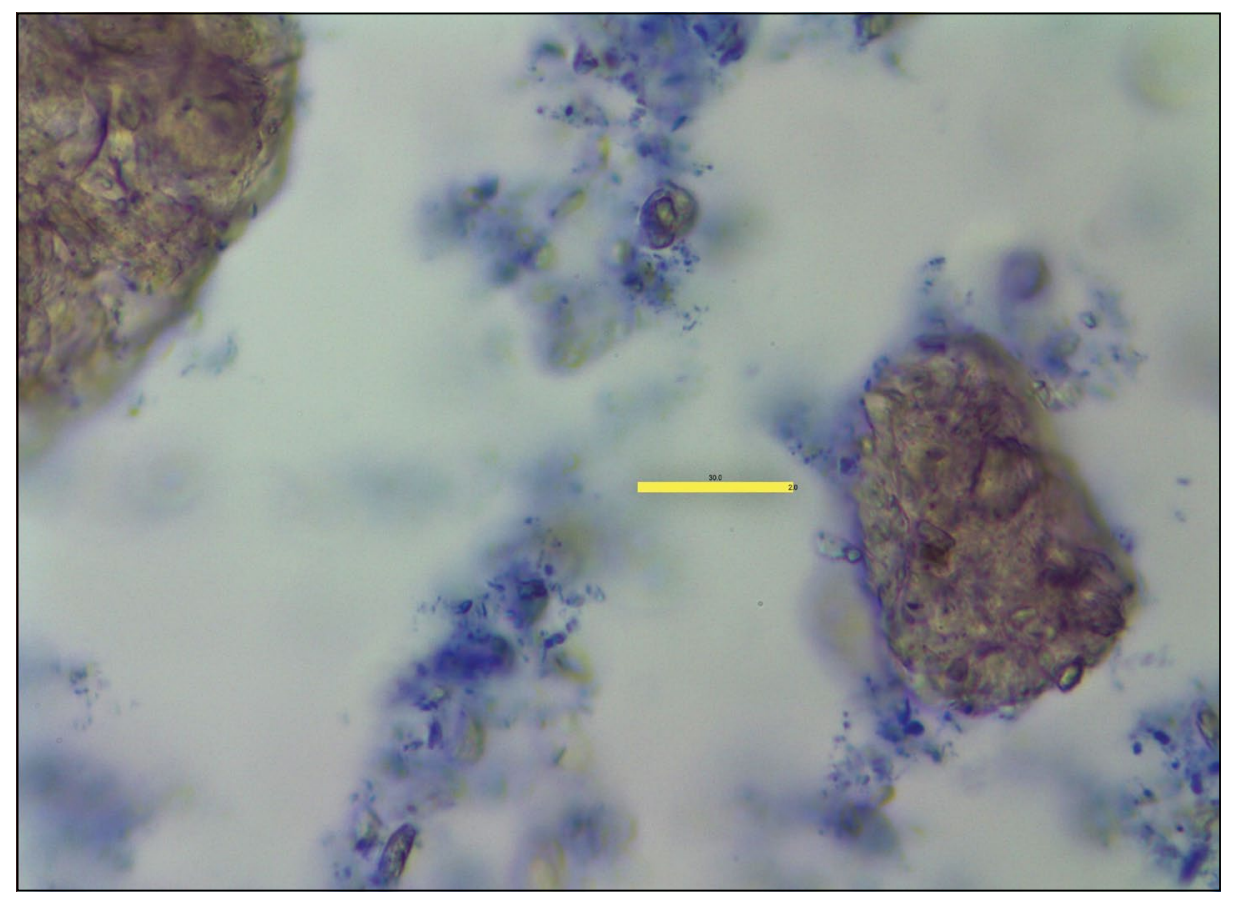

Photograph 2 Olive-grey residual clay, not treated with dispersant, after addition of $3 \mathrm{mg}$ methylene blue per $1 \mathrm{~g}$ of soil

Many of the particles of 2 microns and a little larger adhering to the silt particles show a faint blue outline. Much of the pinkish cloudy area has taken in methylene blue and appears to be composed of extremely small clay particles. Little of the field of view is in focus, but some deeply-stained individual particles smaller than 1 micron are discernible.

state cannot attract each other by fitting electrostatic peaks to troughs. The second way is by reacting with multi-valent ions to form chemical complexes, making them unavailable for attraction to clay surfaces. The third manner is by forming functional groups which act as spacers between the clay particles, effectively preventing them from approaching each other.

The combined action of clay particles, cations and dispersing agents is complex. Above a certain concentration of dispersant the diffused double layer starts to become thinner, repulsion between the particles 
reduces, and at higher concentration turns to attraction, allowing flocculation to occur.

Sodium hexamataphosphate is one of the most popular dispersing agents. It is specified in the standards for assessing clay fraction in Britain, America, Canada, Australia, Japan and other countries. It provides mono-valent sodium ions to coat the clay surface, as well as phosphate groups to form complexes with multi-valent cations. Sodium carbonate may be added to increase alkalinity; this has been found to improve the dispersive efficiency slightly in some circumstances (Rolfe et al 1960) and to extend the useful life of the dispersant (Nettleship et al 1997).

A mixture of sodium hexametaphosphate and sodium carbonate is specified as the dispersant for the hydrometer procedure of SANS 3001 GR3.

\section{BACKGROUND AND AIMS OF THE STUDY}

Investigations are being undertaken by the CUT Soil Mechanics Research Group seeking solutions to the problem of large numbers of failures in government subsidy houses due to heaving foundations. It appears that in some of the failures investigated, the geotechnical investigation had given misleading indications of clay fraction. In one case hydrometer analysis indicated less than $10 \%$ clay on a site where notable shrinkage cracks in the ground surface suggested at least 20\% clay content. Since hydrometer analysis is normal for almost all construction projects in South Africa, such shortcomings in the method may be relevant for a wide range of situations. The aim of this study was to gain an insight into the reliability of the clay fraction indicated by the hydrometer for a range of clays typical of those found in construction projects in South Africa.

It is common practice among researchers to examine clays with an electron microscope. This has the advantage of very high magnification. Preparation involves samples being treated by techniques such as drying and coating with gold (Nettleship et al 1997). This does not replicate conditions in the hydrometer. A series of exploratory tests were conducted at the geotechnical research laboratory of CUT to examine the possibility of using an optical microscope/digital camera combination to investigate the efficiency of the dispersion of clays using method GR3. The results suggested that dispersion was not always satisfactory. Many clay particles appeared to remain as conglomerations, while others remained adhered to silt and sand particles.

The procedures used by soil science laboratories differ somewhat from those for engineering materials. Previous cooperation

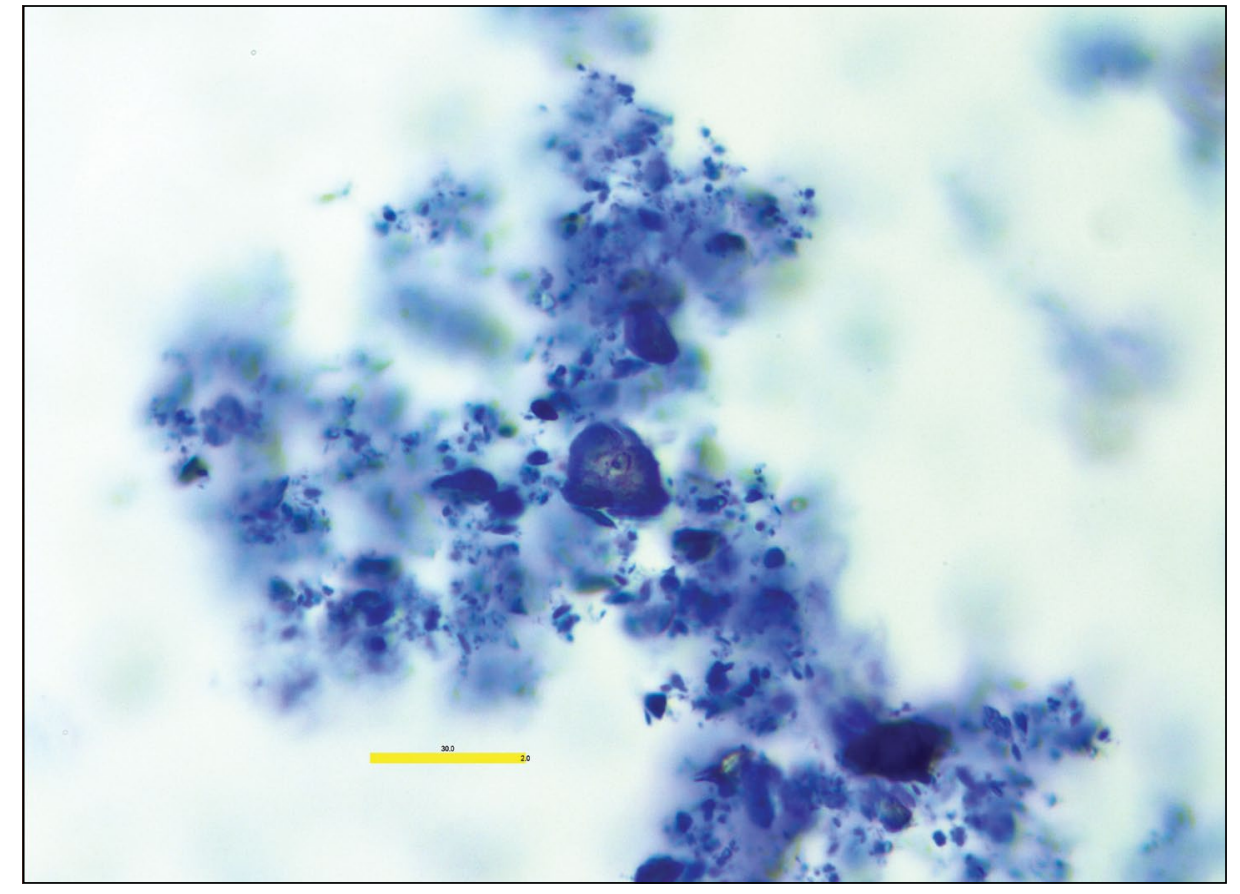

Photograph 3 Olive-grey residual clay not treated with dispersant after addition of $8 \mathrm{mg}$ methylene blue per $1 \mathrm{~g}$ of soil

None of the pinkish cloud remains, it appears to have taken in dye and can be deduced to be an aggregation of very small clay particles. Almost all of the silt particles appear to be completely covered with clay. The assembly moves as a flexible unit in the currents caused by evaporation around the edge of the cover slip. No individual clay particles, which are not part of an aggregation, can be seen.

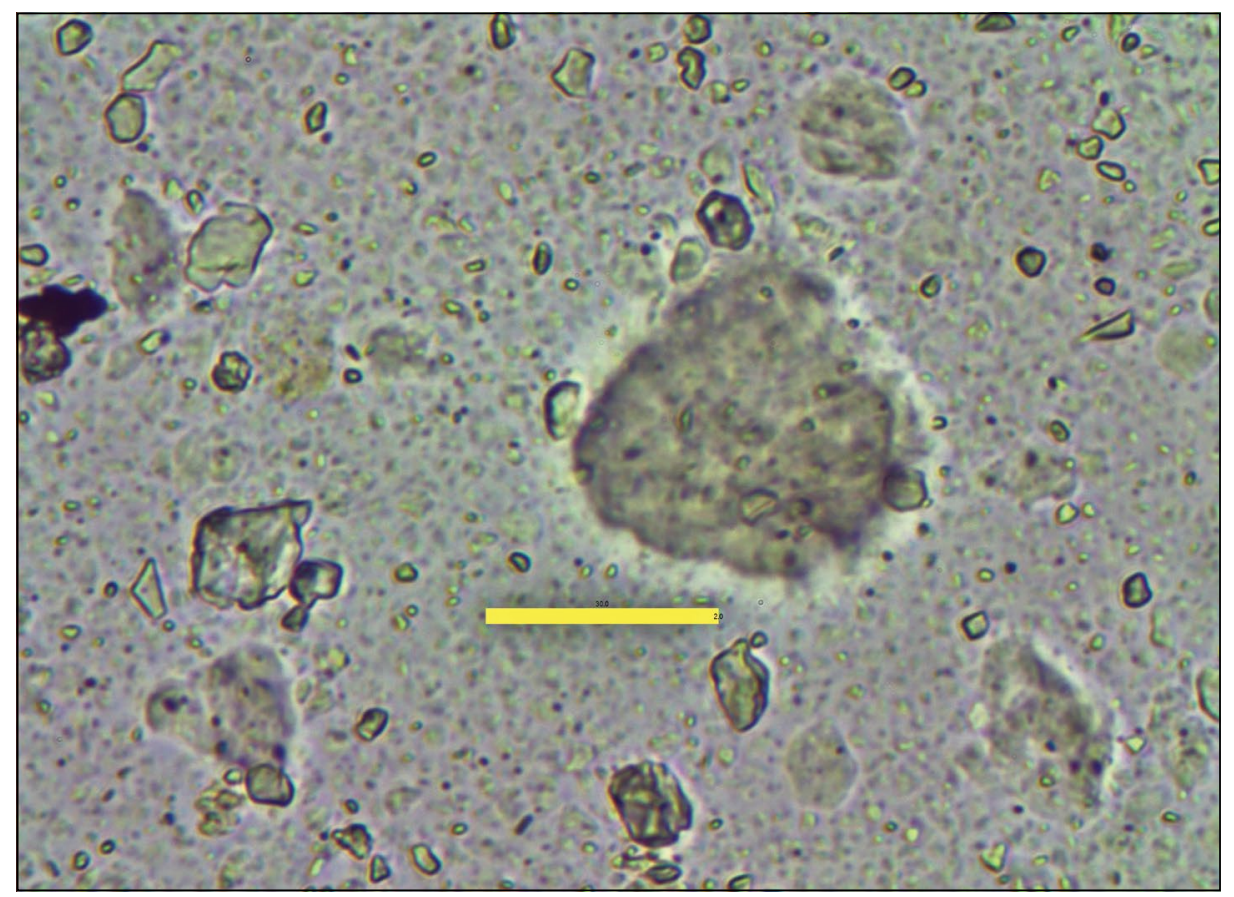

Photograph 4 Olive-grey residual clay treated with dispersant and stirred as specified in SANS 3001 GR3

Many clay-size particles are dispersed but some remain attached to silt particles or form associations of three or more particles not attached to silt.

with the Soil Science Department of the University of the Free State had sometimes found higher clay fractions indicated by their procedures. It was arranged for six samples to be prepared by the UFS soil science laboratory using their normal method. The dispersant is $50 \mathrm{~g}$ per litre sodium hexametaphosphate solution (the amount applied depends on soil type), sonification in a dismembrator is specified for clay soils, and mechanical dispersion is of shorter duration but at a higher speed than SANS 3001 GR3. The samples were examined to determine whether dispersion by this treatment was visibly more effective than SANS 3001 GR3 for these six soils. 


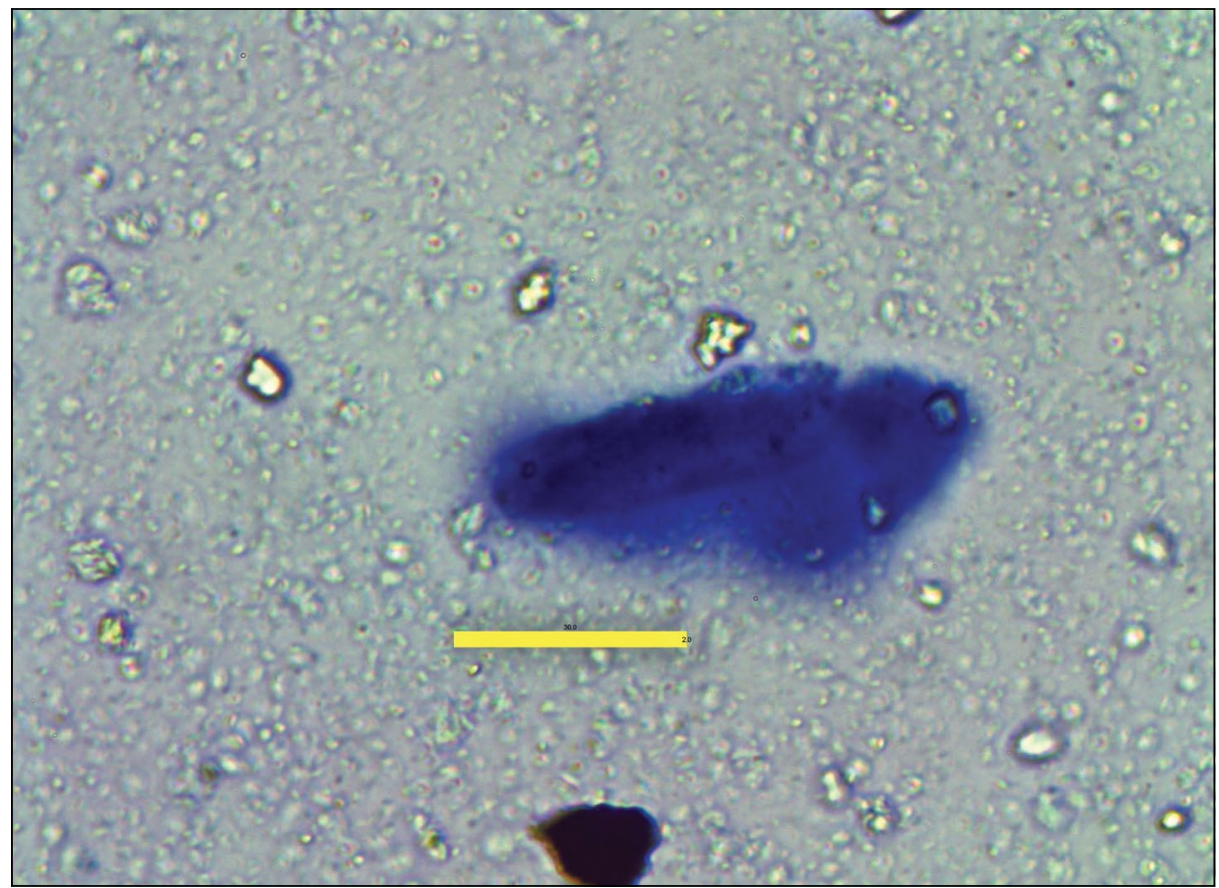

Photograph 5 Olive-grey residual clay treated with dispersant and methylene blue

The small agglomerations of clay-size particles show little, if any, staining, suggesting very low CEC. The silt particle at bottom centre appears to be coated with very small, high CEC particles which are very darkly stained. The deeply stained agglomeration in the centre is about 50 microns in length and 25 microns in width. It appears to be made of very small, high CEC particles, and it seems to engulf several silt and clay-size particles. Such agglomerations were not uncommon in this sample, but probably not common enough to ensure a meaningless clay fraction from hydrometer analysis.

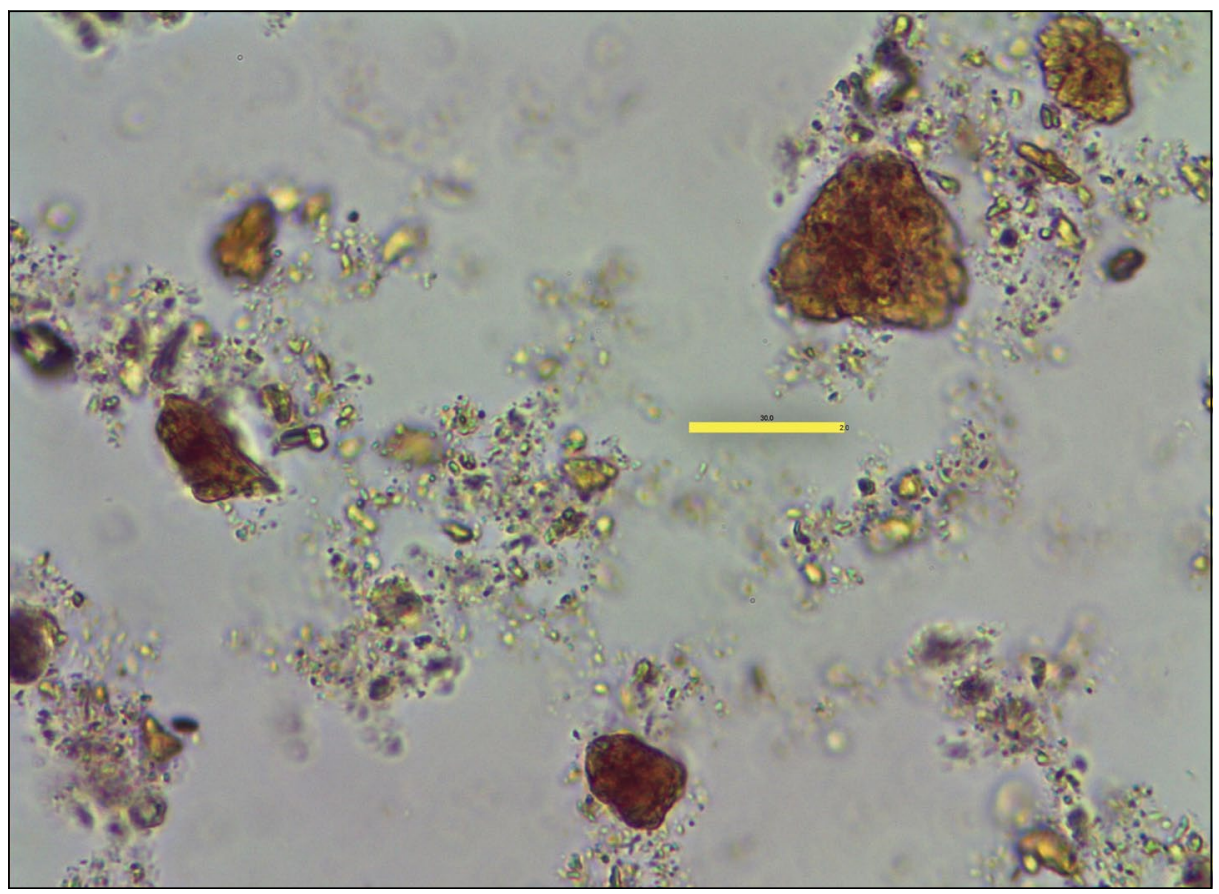

Photograph 6 Red-brown soil from Limpopo after mechanical stirring without addition of dispersing agent

Many of the silt-sized particles appear to have clay-sized particles adhering to them. A faint cloudy pinkish haze, as noted in Photograph 1, is again evident. Most of the silt particles appear to be clustered together in loose associations.

\section{EQUIPMENT, MATERIALS AND THEIR USAGE IN THE INVESTIGATION}

\section{Microscope and camera}

An optical microscope with objectives of $10 x, 40 x, 60 x$ and 100x was equipped with a digital camera (resolution 9 mega pixels). Magnification resulting from the combined effects of the microscope's lenses and the camera was assessed by measurements on a 100 lines/mm diffraction grating.
A drop of sample prepared for hydrometer analysis was placed on a microscope slide, covered with a cover-slip and photographed at various magnifications.

Photographs were taken at various locations on the slide. Most of the photographs in this investigation were taken using the microscope's 40x objective since more powerful lenses give a very small depth of focus.

\section{Magnification}

The combined optical and digital magnification can be defined in different ways. The computer screen that was used to view the images showed lines spaced at 10 microns on the diffraction grating, spaced at $40 \mathrm{~mm}$ on the screen when using the $40 \mathrm{x}$ objective. This implies a magnification of 4000 times. Alternatively, the 10-micron spacing on the diffraction grating corresponds to 150 pixels on the photographs produced by the camera using the same objective. The most convenient way of indicating magnification is by incorporating a reference object of known size. All of the photographs in this article have a rectangle superimposed to indicate the scale. The length and breadth of each rectangle represent 30 microns and 2 microns respectively.

\section{Variations in procedure}

Samples were also prepared employing variations to the normal procedures in order to examine the influence of time of soaking in dispersant, time of agitation, concentration of dispersant and volume of dispersant used. Method GR3 specifies only minimum times of soaking and agitation. All of the times involved are within these specifications, and this part of the investigation served only to verify whether this aspect of the specification is adequate. Examination of the concentration of dispersant was prompted by the finding of a difference in hydrometer yield for certain clays using the Japanese and American standards, which specify different concentrations of sodium hexametaphosphate (Mishra et al 2011).

\section{Methylene blue}

In addition, samples were treated with methylene blue (MB), with the aim of labelling clay particles for positive identification. Methylene blue $\left(\mathrm{C}_{16} \mathrm{H}_{18} \mathrm{~N}_{3} \mathrm{SCl}\right)$ is an effective indicator of clay, as it readily exchanges places with cations in the clay mineral structure, the amount depending on the cation exchange capacity (CEC) and specific surface area (SSA) of the clay minerals (Turoz \& Tosun 2011). Active clays like montmorillonite have high CEC and SSA, and readily take in methylene blue. When $\mathrm{MB}$ is available in large concentrations, 
such clays rapidly become totally opaque and appear in photographs as dark blobs in which no structure can be seen. Inactive clay minerals like kaolinite have low CEC and SSA and show little colouring until high CEC/SSA fractions present are already deeply stained. Progressive addition of small amounts of dye can therefore give an indication of the types of clay mineral present in a sample, and can also help to establish whether the clay-size particles which can be seen adhering to silt and sand particles are, in fact, composed of clay minerals. Any additive to the soil solution which affects the cation balance will inevitably influence the effectiveness of the dispersant. Only small quantities of methylene blue were therefore added to the dispersed samples. It could be expected that silt and sand would not be coloured, and high CEC / high SSA clays (e.g. montmorillonite) would be coloured after adding very little dye, whereas low CEC / low SSA clays (e.g. kaolinite) would be coloured only after the addition of considerably more dye.

\section{THEORETICAL CONSIDERATIONS AND STRENGTHS / WEAKNESSES OF THE METHOD EMPLOYED}

Soil mechanics and soil science generally consider all particles of 2 microns and smaller to be clay-size particles, and those from 2 microns to 60 microns (or some other arbitrary figure of this order) to be of silt-size. But particles and agglomerations of clay minerals typically range from about 0.1 micron to slightly more than 2 microns; non-clay particles typically range from about 1 micron upwards (Robinet et al 2011). Some clays, e.g. kaolinite and haloysite, may have particles considerably larger than 2 microns, as can be seen in electron micrographs by Bühmann and Kirsten (1991). There is thus a range where size classification may not correspond with mineral classification. Certain important aspects of soil behaviour (e.g. volume change) depend on clay mineral content, while hydrometer and pipette analyses attempt to establish only particle sizes, not mineral content. Many of the individual particles observed were in this ambiguous range of 1 to 2 microns, raising the question of whether they are clay particles which need to be dispersed, or silt particles which do not flocculate and should not need dispersion.

The magnifications possible with the optical microscope and camera combination used in this investigation are probably sufficient to distinguish most of the range typical for clay through silt to sand, but not

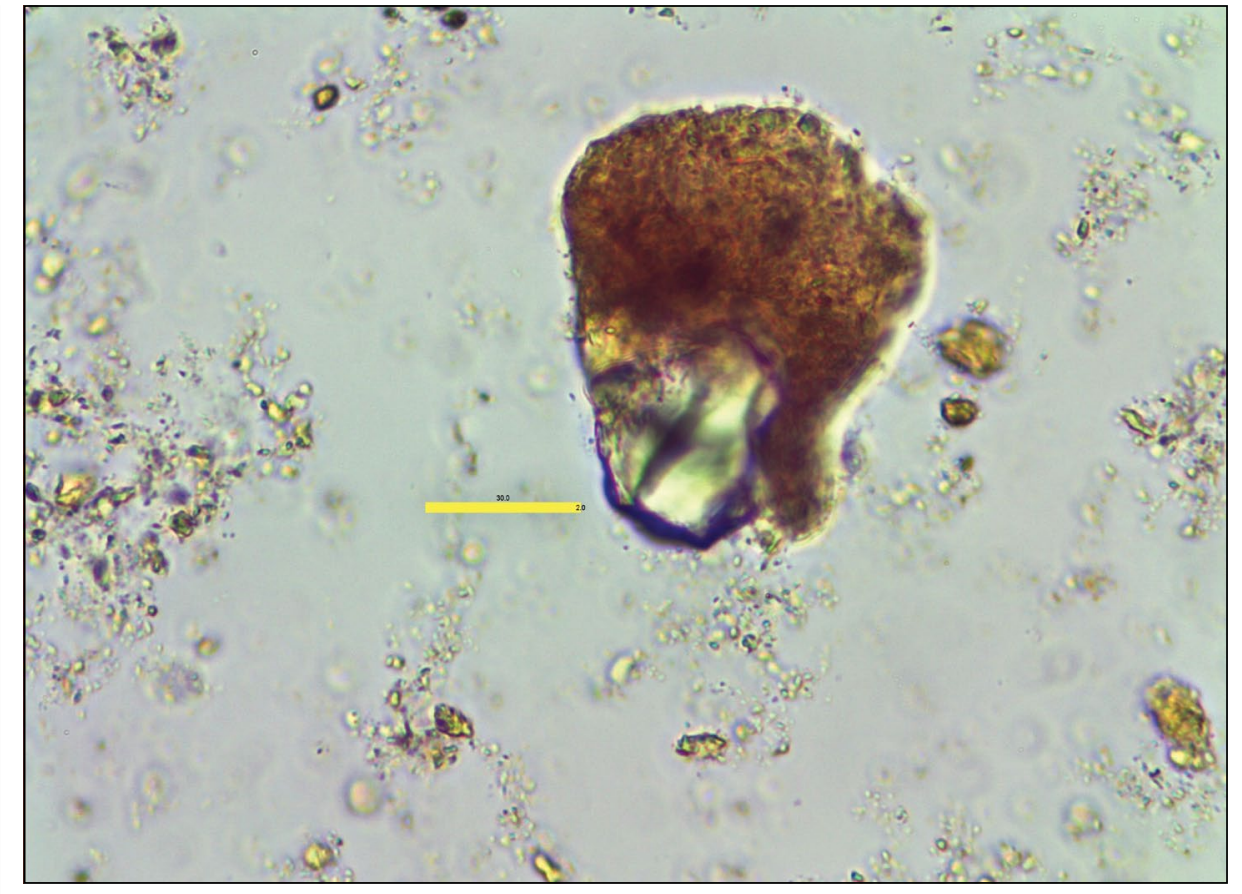

Photograph 7 Red-brown Limpopo soil as in Photograph 6 after stirring without dispersant

The large silt/sand particle appears to have lost part of its coating of clay-size particles. The pinkish haze and loose groupings of silt particles are again evident.

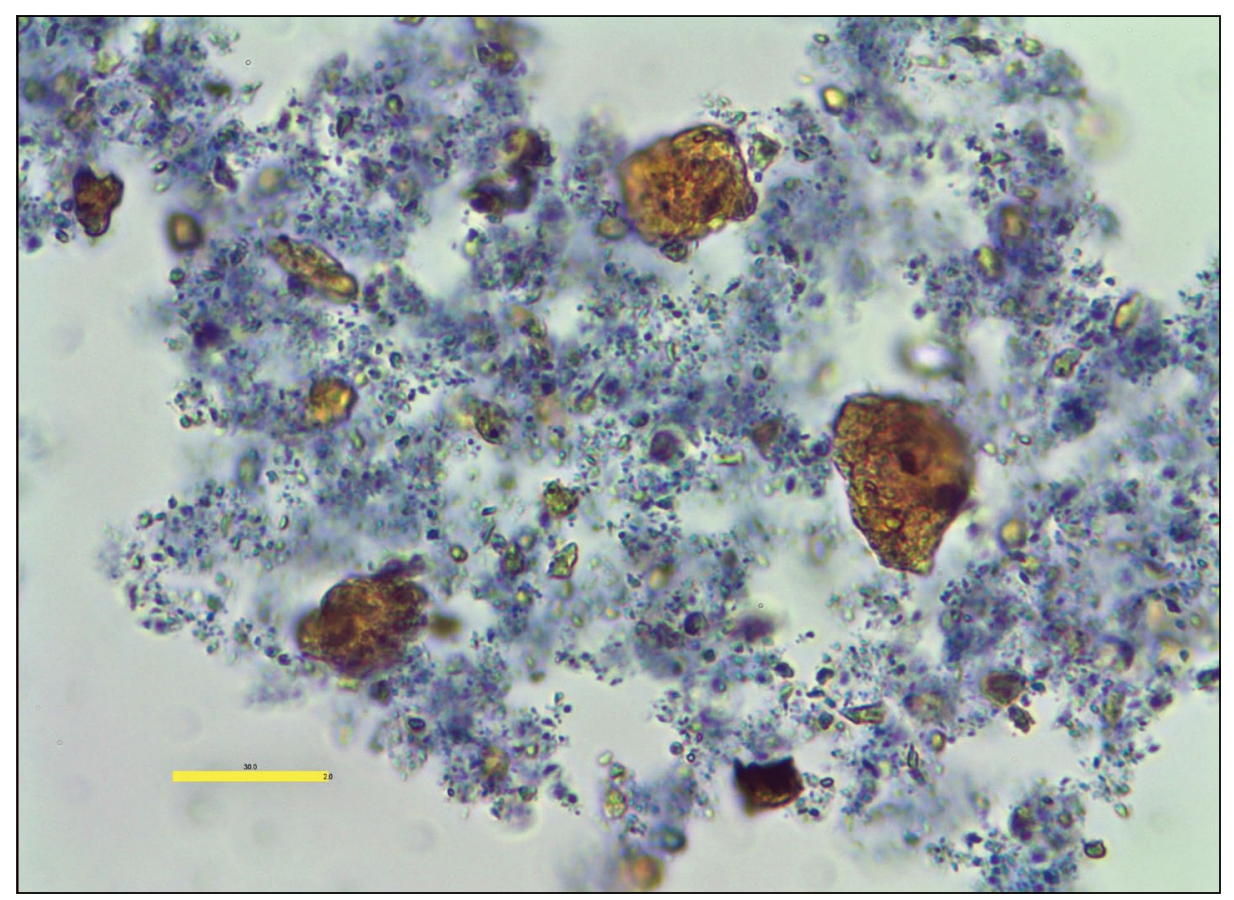

Photograph 8 Red-brown soil from Limpopo after addition of $3 \mathrm{mg}$ methylene blue per gram of soil The pinkish cloud appears to have absorbed methylene blue, revealing itself to be an extensive agglomeration of small clay particles, as in the case of the olive-grey clay in Photographs 1,2 and 3. Most of the silt grains which appear to be covered with clay-size particles have scattered spots of dark blue stain suggesting a few high CEC clay particles among many low CEC particles.

adequate to measure the smallest particles in this range. Since all samples remained in aqueous suspension, all of the smaller individual particles were subject to Brownian motion. At the highest magnification (100x objective -37.5 pixels per micron, $10000 x$ magnification on the computer screen), particles at the lower end of the clay-size range could be distinguished in many of the samples, but their Brownian motion hindered observation or measurement since they suddenly appear in the focal plane, and disappear as they move away from the focal plane. Photographing them was not very successful, possibly because the exposure time of the camera/computer combination was too long. Many small particles were visible and could be photographed where they formed part of large agglomerations or were attached to silt or sand particles. 


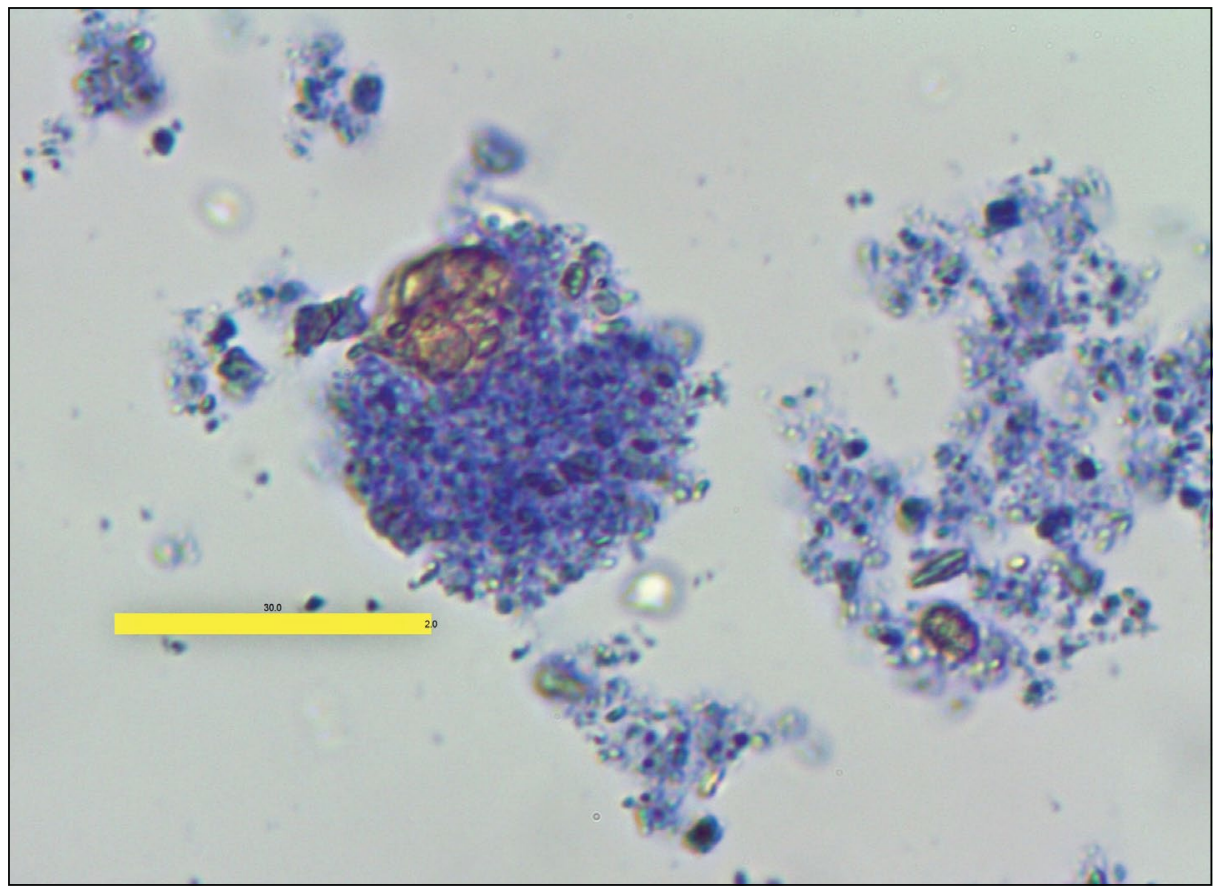

Photograph 9 Red-brown Limpopo soil mechanically stirred (without treatment with dispersant) and subsequent addition of $6 \mathrm{mg}$ of methylene blue per gram of soil

The dense mass of deeply stained clay particles appears to almost completely engulf a silt particle covered with barely stained clay-size particles.

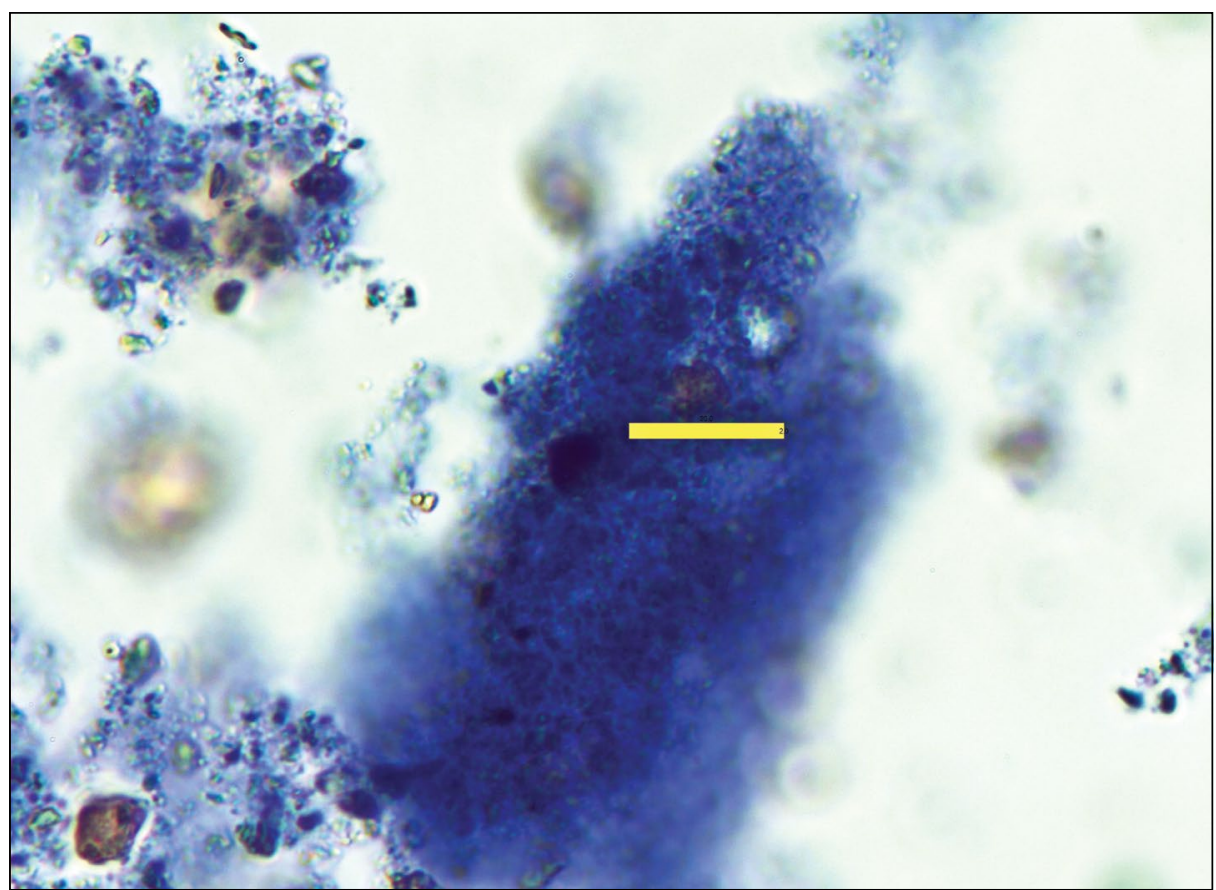

Photograph 10 Red-brown Limpopo soil not treated by dispersant with $6 \mathrm{mg} / \mathrm{g}$ methylene blue added

The large blue structure is more than 150 microns by 50 microns in size. Within this

structure silt particles can be distinguished. Much of the agglomeration appears to consist of clay particles of about 1 micron or smaller. The agglomeration slightly above and left of centre appears to consist almost entirely of a different species of clay particles of about 2 microns which are very lightly stained. Very few soil particles are visible which are not part of an agglomeration.

\section{GENERAL CONSIDERATIONS}

The following considerations in terms of the microscopic investigation should be noted:

1. Those samples extracted for microscopic investigation at the UFS laboratory were taken by pipette after a settling time calculated to give only silt- and clay-sized particles at the depth of extraction (larger particles having settled below this level). The largest particle sizes measured were of the order 50 microns, suggesting that the sample was, indeed, restricted to clay and silt-sized particles. Samples prepared in the CUT laboratory were taken immediately after agitation, and some samples contained particles considerably larger than 50 microns, allowing examination of sand grains as well as silt.

2. The cover slip over the sample was supported by the largest particles, and consequently a depth of about 50 microns was filled with suspension for the UFS samples, and up to about 100 microns for the CUT samples. Depth of sharp focus at high magnification is far smaller than this and consequently photographs necessarily had most of their field out of focus.

3. Since clay sizes range from 2 microns downwards, the concentration of suspension specified in the hydrometer method allows too many clay particles in a depth of 50 microns for convenient optical differentiation. This made dilution of the hydrometer samples necessary. The majority of samples were diluted with three times their own volume of de-ionised water. This dilution was arbitrarily chosen and was considered adequate for this purely qualitative investigation.

4. The gap of approximately 50 to 100 microns between slide and cover slip allows evaporation of the suspension's water around the edges. It may be possible to seal around the edge of the cover slip and prevent evaporation, but it was found that the movement of water caused by evaporation was helpful in distinguishing between clay-size particles which were dispersed and free-floating, and those which were attached to silt or sand particles or formed agglomerations with other clay particles. This consideration results in a very limited time available for the observation of each slide.

5. When samples dry out they conglomerate, making it difficult to draw conclusions about the behaviour of the clay in conditions relevant to the pipette and hydrometer tests. Only observations in suspension conditions were considered in this investigation.

\section{SAMPLES USED IN THE INVESTIGATION}

Samples of six widely different clay soils (from the Free State, Northern Cape, Western Cape and Limpopo) were mechanically agitated, as in procedure GR3, but without first soaking in dispersant. Samples of the same soils were prepared with both dispersant and mechanical agitation at CUT, as per SANS 3001 GR3, and at the Soil Science Laboratory of UFS using standard soil science procedures. From the six soils, two were selected as showing typical features and illustrating the general effectiveness of the investigation's procedures. One soil appeared to show fair dispersion, the other 
very inadequate dispersion. The first of these samples is shown in Photographs 1 to 5 , the second in Photographs 6 to 13 . They provide a reference frame and show widely different clays with and without dispersant, both with and without methylene blue. Features of some of the other soils are shown in the remainder of the photographs.

\section{OBSERVATIONS}

Photograph 1 is of an olive-grey residual clay from a proposed housing development in Bloemfontein. Tests at the UFS Soil Science Laboratory gave LL 72, PI 26 and clay fraction $41 \%$ (by both hydrometer and pipette methods). Photograph 2 shows the same sample after the addition of $3 \mathrm{mg}$ of MB per gram of soil. Photograph 3 shows the same sample after the addition of a further $5 \mathrm{mg} / \mathrm{g}$ of MB dye.

It appears that a large number of very small clay particles bind considerable numbers of various kinds of particles into associations. Currents caused by evaporation of the suspension's water show that these associations are flexible, but strongly tied together and move as a unit.

Photograph 4 shows the same soil after treatment with dispersant as specified in SANS 3001 GR3. Comparison with Photograph 1 shows a very large increase in clay-size particles dispersed throughout the water. There are, however, some clay-size particles adhering to silt particles, and a number of small agglomerations of clay-size particles with no visible silt core.

Photograph 5 shows this same dispersanttreated sample after the addition of methylene blue. While this sample shows good dispersion compared to the untreated state, it is apparent that dispersion is not complete. The majority of dispersed particles appear to be about 2 microns in size, but small, deeply stained particles of less than 1 micron can also be seen, and it is difficult to discern whether they are free or attached to larger clay-size particles. The agglomerations of clay-size particles, the clay-coated silt particles and the agglomeration of very fine clay will probably not precipitate at a rate which will ensure their contribution to the clay fraction being recorded by the hydrometer.

Photograph 6 is of a red-brown soil from the Limpopo Province, which has a history of giving variable results in soil tests and causing difficulties in construction. Treatment was only mechanical stirring of the raw soil without dispersant. Commercial laboratory results for samples sent by CUT as part of a parallel testing programme ranged between $17 \%$ and $56 \%$ for clay fraction, and between 31 and 43 for PI.

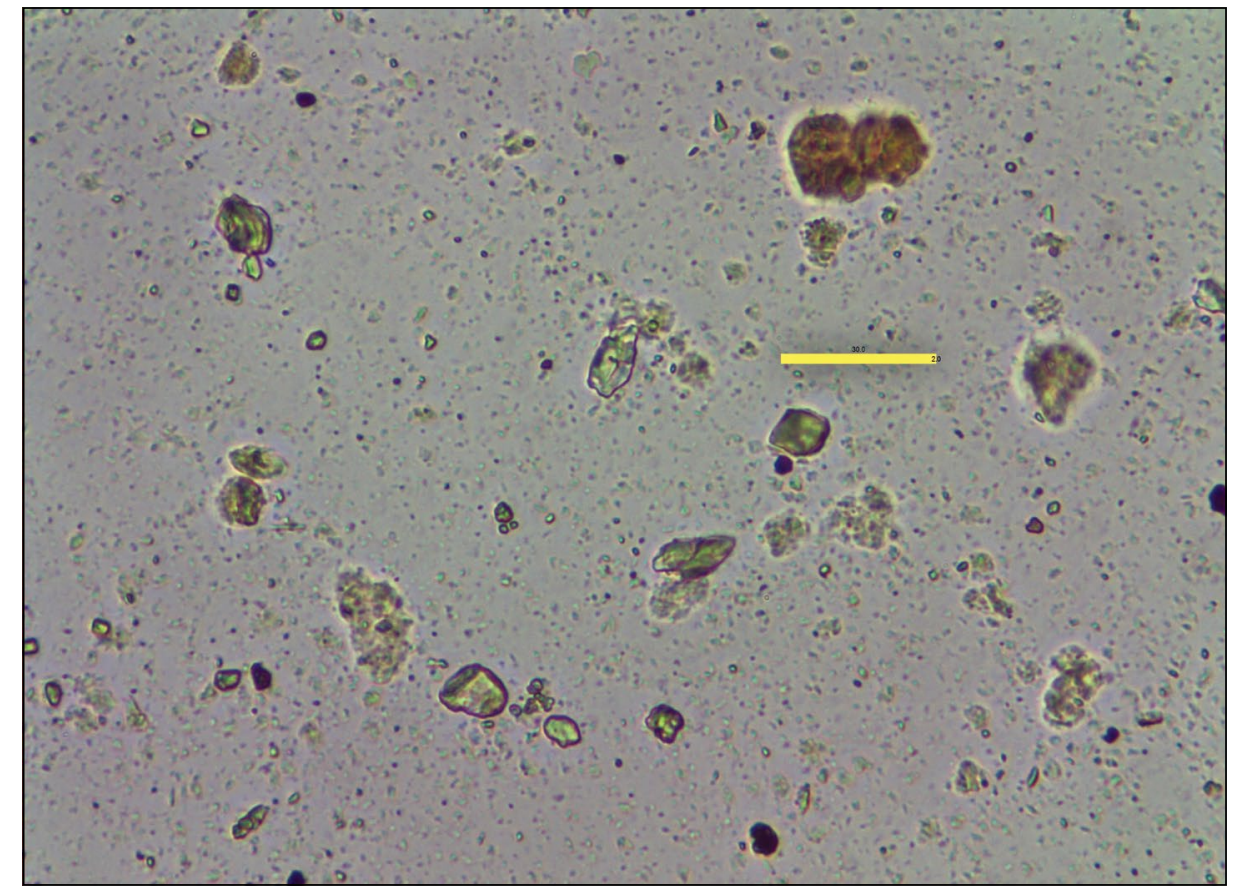

Photograph 11 Red-brown Limpopo soil after treatment with dispersant at the UFS Soil Science Laboratory

Many clay-size particles are well dispersed, but a substantial number remain attached to silt particles. There are also cloudy pinkish areas similar to those in Photograph 1.

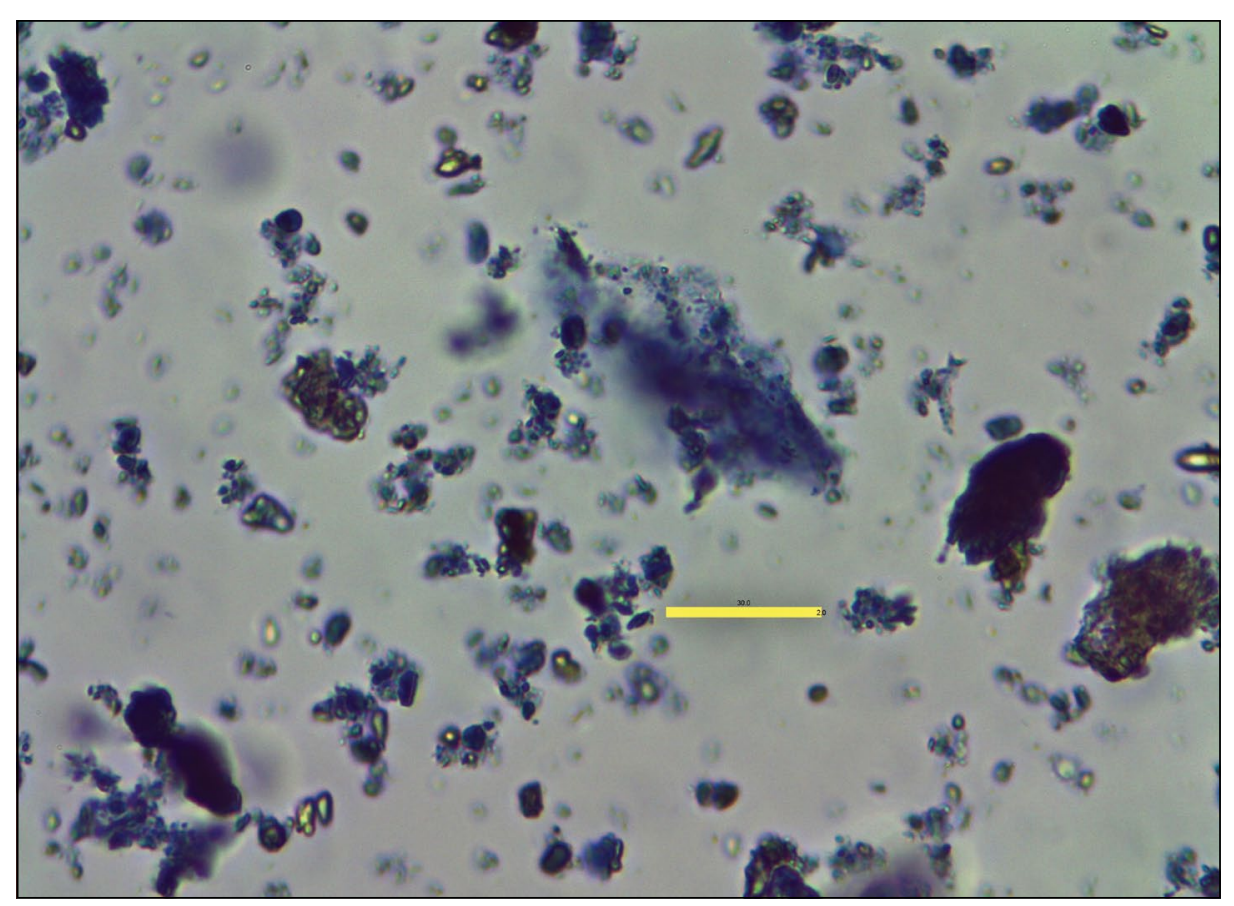

Photograph 12 Same sample as Photograph 11 after addition of methylene blue

As in the case of the olive-grey

Bloemfontein soil there are shadowy pinkish bands associated with the distinctly visible particles. There are also many clay-size particles adhering to most of the silt-size particles.

In Photograph 7 a large grain of silt appears to be mostly covered with clay-size particles. Part of the grain, however, is completely clean and free from clay coating. It is possible that it was struck by one of the paddles of the mechanical stirrer and some of the coating was torn away. The coating of the lower right area seems to have come loose from the large particle, but remains attached to the clay coating above.

Photograph 8 shows the same sample after addition of $3 \mathrm{mg} / \mathrm{g}$ of methylene blue. A few small blue spots are visible on the larger silt-sized particles, but the majority of particles of about 2 microns remain unstained. A clearly visible cloud of very small bluestained particles has largely replaced the faint pink cloud, suggesting that the cloud consists of very small and possibly translucent clay particles with high CEC/SSA.

Photographs 9 and 10 show the same sample after the addition of a further $3 \mathrm{mg} / \mathrm{g}$ 


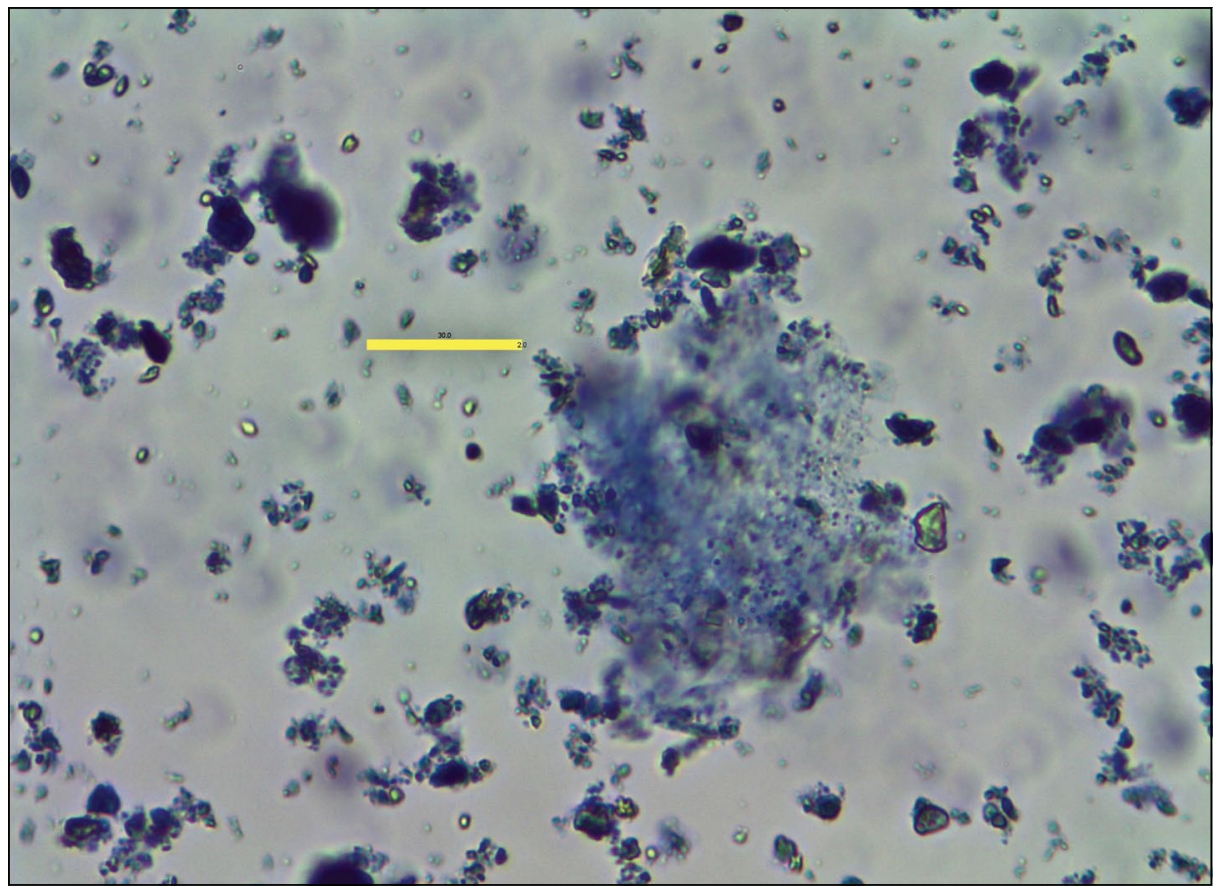

Photograph 13 Same sample as Photograph 12

The dispersion and agitation procedures have produced many well-dispersed clay particles, but the large agglomeration shown here is far from dispersed. This sand-size grouping of silt and clay is unlikely to settle at the rate expected of clay, nor are the numerous smaller aggregations.

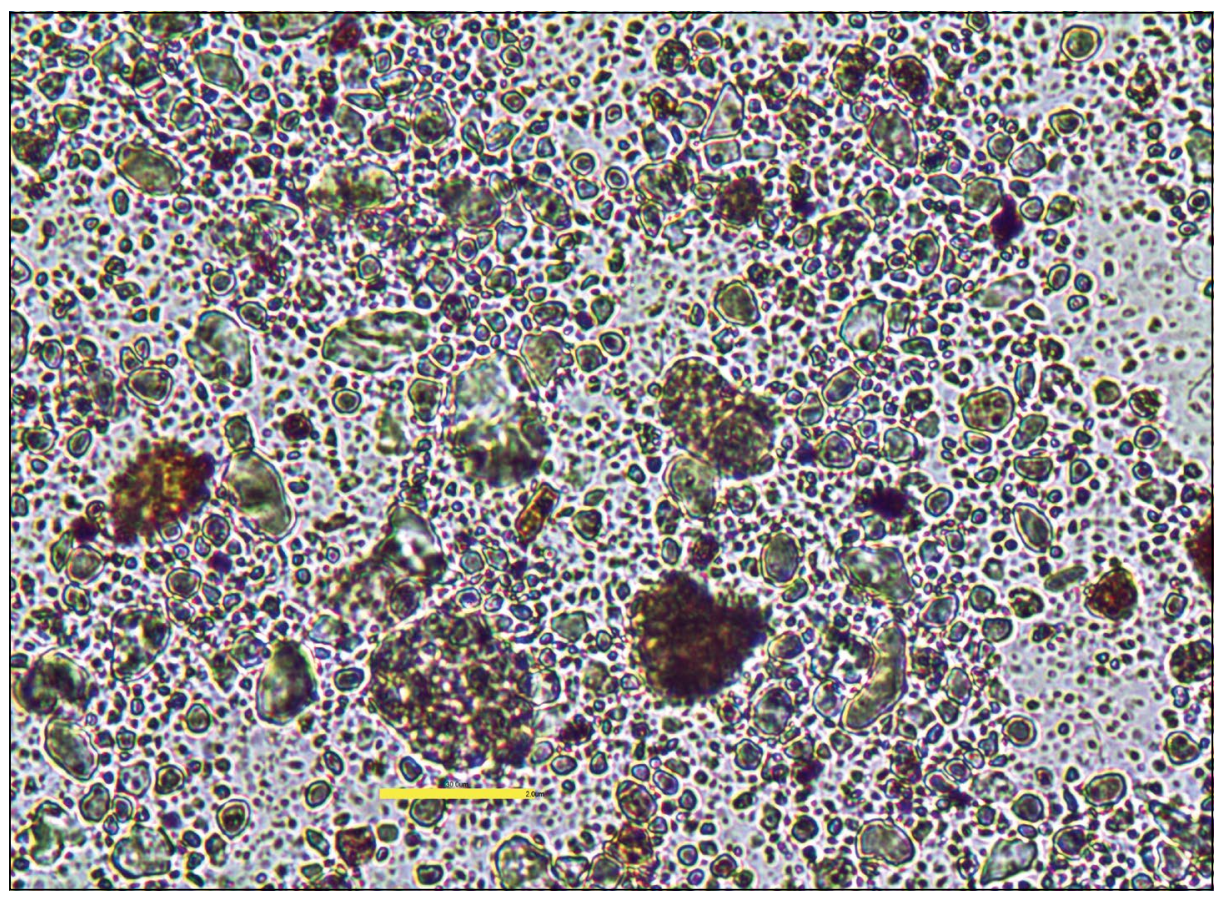

Photograph 14 Soil from a subsidy housing project in the Northern Cape after treatment with dispersant and mechanical agitation at the UFS Soil Science Laboratory

The majority of silt particles remain covered with clay-size particles.

of methylene blue. Photograph 9 shows a grain of silt, apparently covered with low CEC clay, almost completely enveloped by high CEC clay particles. A number of small clay particles appear to be dispersed into the surrounding water, but the majority are associated with aggregations. In Photograph $10 \mathrm{a}$ large agglomeration of clay appears to contain several small silt particles of various types.

Photograph 11 shows a sample of the same soil treated with dispersant. Many small clay particles are dispersed, and, compared to Photographs 6 and 7, the groupings of silt particles have largely disappeared. Yet many of the slit particles remain totally or partially coated with clay-size particles, and many agglomerations of two or more claysize particles can be seen.

Photographs 12 and 13 show the same soil after addition of methylene blue. Compared to Photographs 9 and 10, where no dispersant was used, dispersion is clearly improved, but most of the silt particles are seen to be covered with clay, and the faint pinkish clouds again appear to be revealing themselves as very fine clay particles which are not well dispersed and may settle in the hydrometer as silt-size aggregates rather than as individual clay particles.

Photograph 13 shows an exceptionally large agglomeration of small clay particles engulfing several silt particles and numerous 1 to 2 micron clay particles against a background of well-dispersed clay particles. Nettleship et al (1997) came to the conclusion that their anomalous observations of settlement in the hydrometer might be explained by agglomeration taking place while particles were settling during the test. It seems more likely that this could be the case here than that such an agglomeration could have survived 15 minutes of stirring at $1500 \mathrm{rpm}$ after prolonged soaking in dispersant.

The amount of clay which is obviously not dispersed in Photographs 12 and 13 suggests that it is very unlikely that the hydrometer will give a reliable estimate of the true clay fraction of this soil.

Photograph 14 shows a soil from a housing project in the Northern Cape. Hydrometer analysis had shown the clay fraction for almost all of the samples from this site to be very low. This led to a low value of Van der Merwe's predicted heave being accepted for design. Heave damage did, however, occur on the project.

A considerable fraction of the clay-size particles visible in the photograph are attached to silt particles of various sizes. It is not clear whether all the agglomerations of clay-size particles have a silt core, but it appears that much of the clay in this sample has not been dispersed. Hydrometer analysis could underestimate the clay content quite drastically. This might explain the unexpected damage which occurred at the housing project.

Another sample, from less than $100 \mathrm{~m}$ away, was prepared according to SANS 3001 GR3 at the CUT laboratory. A house had become structurally unsound due to heave while still under construction a few metres from where this sample was taken. Photographs 15 and 16 are of this sample. In Photograph 15 many of the visible clay-sized particles are attached to silt particles. It appears that the large congregation of claysized particles in Photograph 16 surrounds a root hair or similar thin, thread-like structure.

Considerably more clay is undispersed than is dispersed. This would suggest the likelihood of a misleading estimate of clay fraction by the hydrometer method.

Photograph 17 shows a low-activity kaolinitic soil described as "light yellow silty clay" from the Western Cape after 
dispersion and addition of methylene blue. It has LL 34, PI 13 and LS 4.6 suggesting that its heave potential is very low. All of the clay particles are about 2 micron or slightly larger in size, which is consistent with the clay being kaolinite. This is the only sample tested which showed no small, high CEC clay particles; all of the other samples showed a range of sizes and probable clay mineral types. Many agglomerations of clay particles are evident. Since it is unlikely that these will settle at the rate expected of individual clay particles, the clay fraction determination is again likely to be unreliable. The description "silty clay" seems inappropriate, since little, if any, silt is evident. The agglomerations of clay are, however, of silt size and it could be that they had settled in the hydrometer at the rate expected of silt-size particles and had been incorrectly assessed as silt.

\section{ADDITIONAL TESTS}

Although it appears that one or two of the samples tested showed fair dispersion (as in Photographs 4 and 5), none showed unquestionably satisfactory dispersion (i.e. little or no clay-sized material forming agglomerations or associations with other particles). Some showed very poor dispersion (as in Photographs 12 to 16). Tests at the CUT geotechnical research laboratory were carried out to assess the effect of concentration of dispersant, volume of dispersant, length of time of submersion in dispersant and time of mechanical agitation. The GR3 procedure includes only minimum times for soaking and agitation, so this served only to check the adequacy of this aspect of the specification.

SANS 3001 GR3 calls for a minimum of 16 hours submersion in the dispersing agent. Various periods from 16 hours to 2 weeks were tested. No visible improvement in dispersion was observed.

SANS 3001 GR3 calls for a minimum mechanical stirring time of 15 minutes at $1500 \mathrm{rpm}$. Various periods from $15 \mathrm{~min}$ utes to 24 hours were tried with no visible improvement in dispersion observed. This tends to confirm that the specified minimum times are adequate.

No visible improvement in dispersion was observed by doubling the quantity of dispersant used to treat the samples or by increasing the concentration of dispersant from $40 \mathrm{~g} / \mathrm{l}$ to $60 \mathrm{~g} / \mathrm{l}$. This was not unexpected, since the UFS samples used $50 \mathrm{~g} / \mathrm{l}$ and showed no visibly significant improvement in dispersion from the GR3 samples.

Samples taken from suspensions permitting little time for settlement, allowed assess ment of the dispersion of clay particles from sand-size particles. Dispersion appeared to

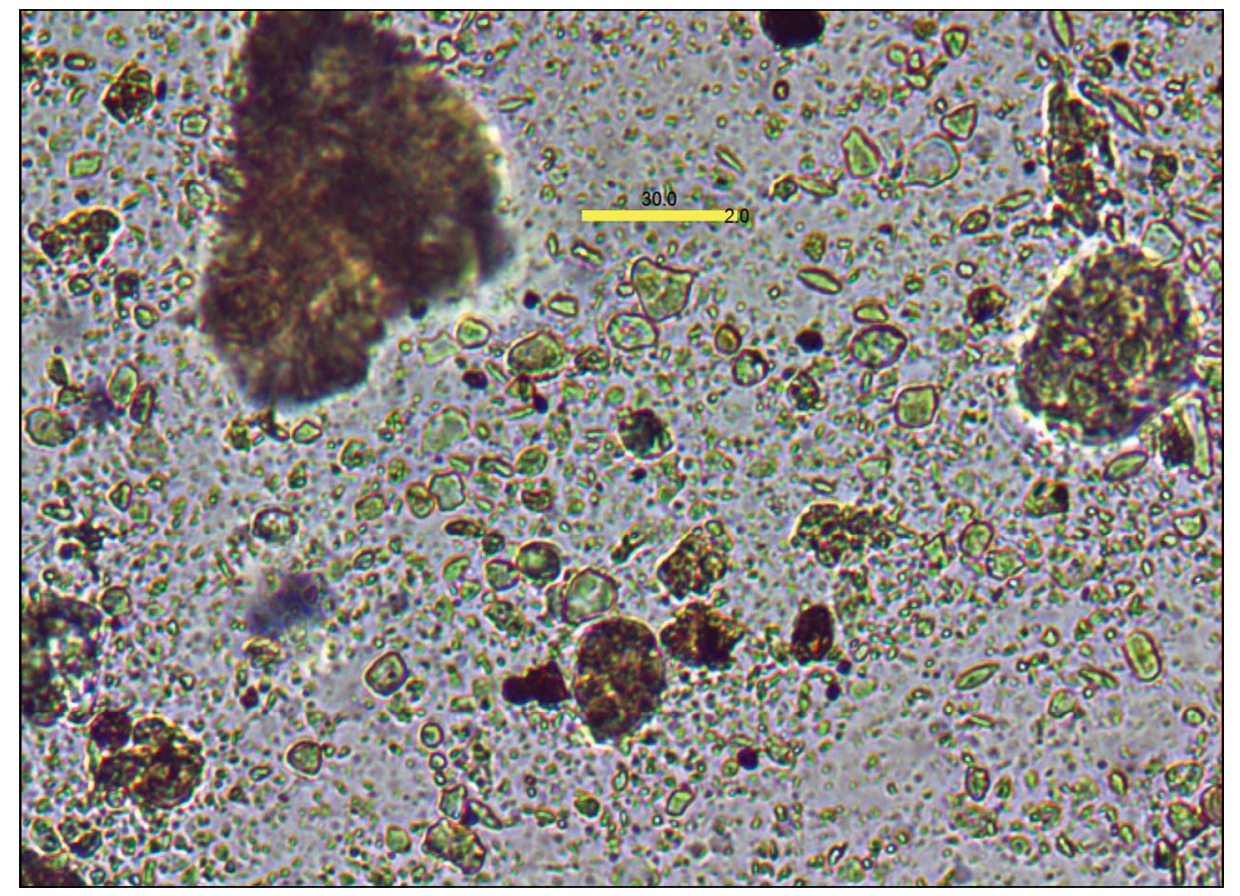

Photograph 15 Sample of soil from the Northern Cape after soaking in dispersant and mechanical agitation as specified by SANS 3001 GR3

This sample was taken a few metres from where a house became structurally unsound due to heave and was demolished before the roof was installed. Soil apparently identical to this from a nearby test pit was assessed by hydrometer as containing only $6 \%$ clay. Many apparently clean silt particles can be seen, as can many dispersed particles smaller than 2 microns. The larger particles are all covered with clay-size particles.

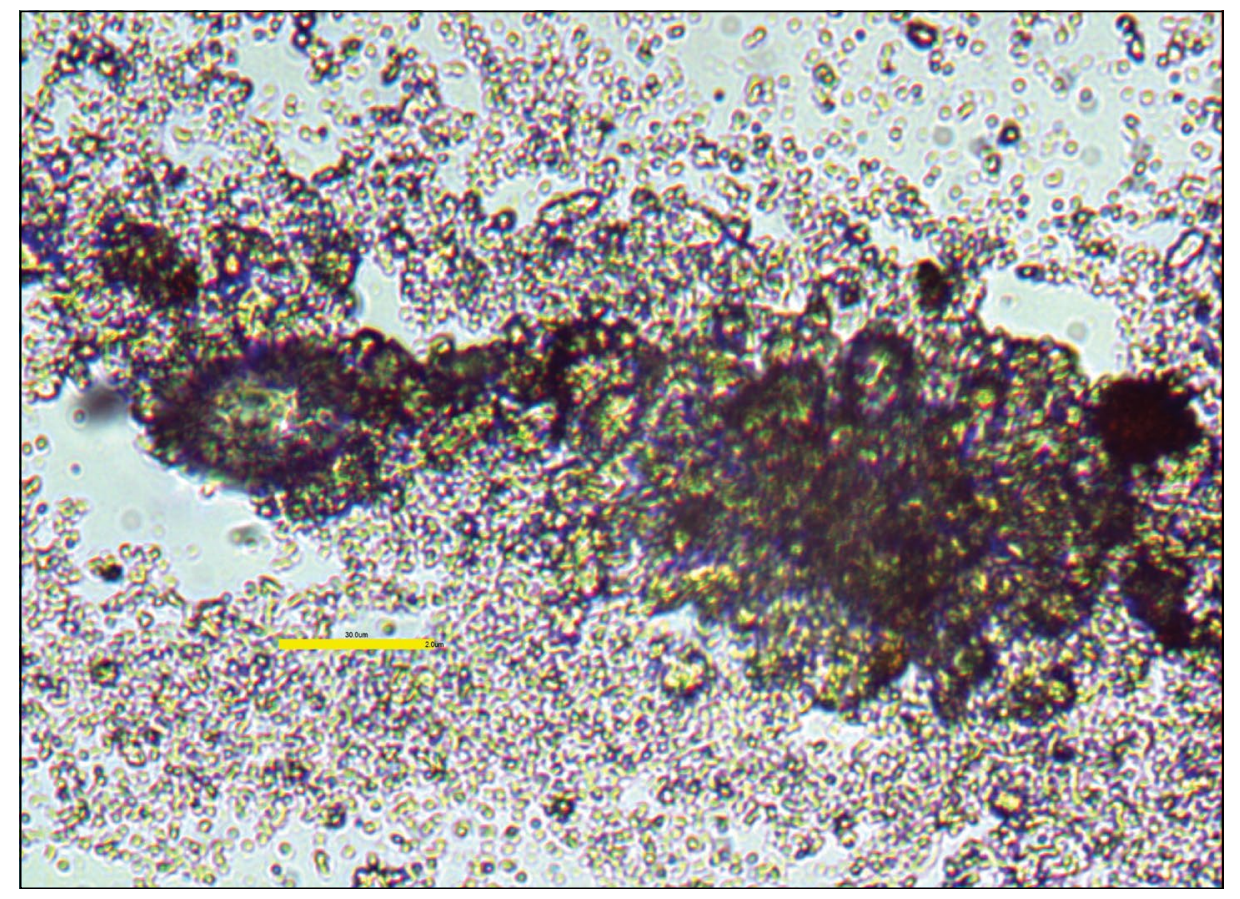

Photograph 16 Same sample as Photograph 15 after treatment with dispersant and mechanical stirring

A large number of clay-size particles form an agglomeration around a thin, thread-like structure - possibly a root-hair - while towards the top right many similar size particles appear to be well dispersed.

be no better than from silt, as can be seen in Photograph 18.

With particles as large as this, the depth of the suspension between slide and cover slip is so great that very little of the suspended material is in focus. It appears that treatment with dispersant and subsequent mechanical agitation had failed to dislodge clay particles from the sand grain.

\section{DISCUSSION}

All of the clays tested showed some lack of dispersion. Every sample showed instances 


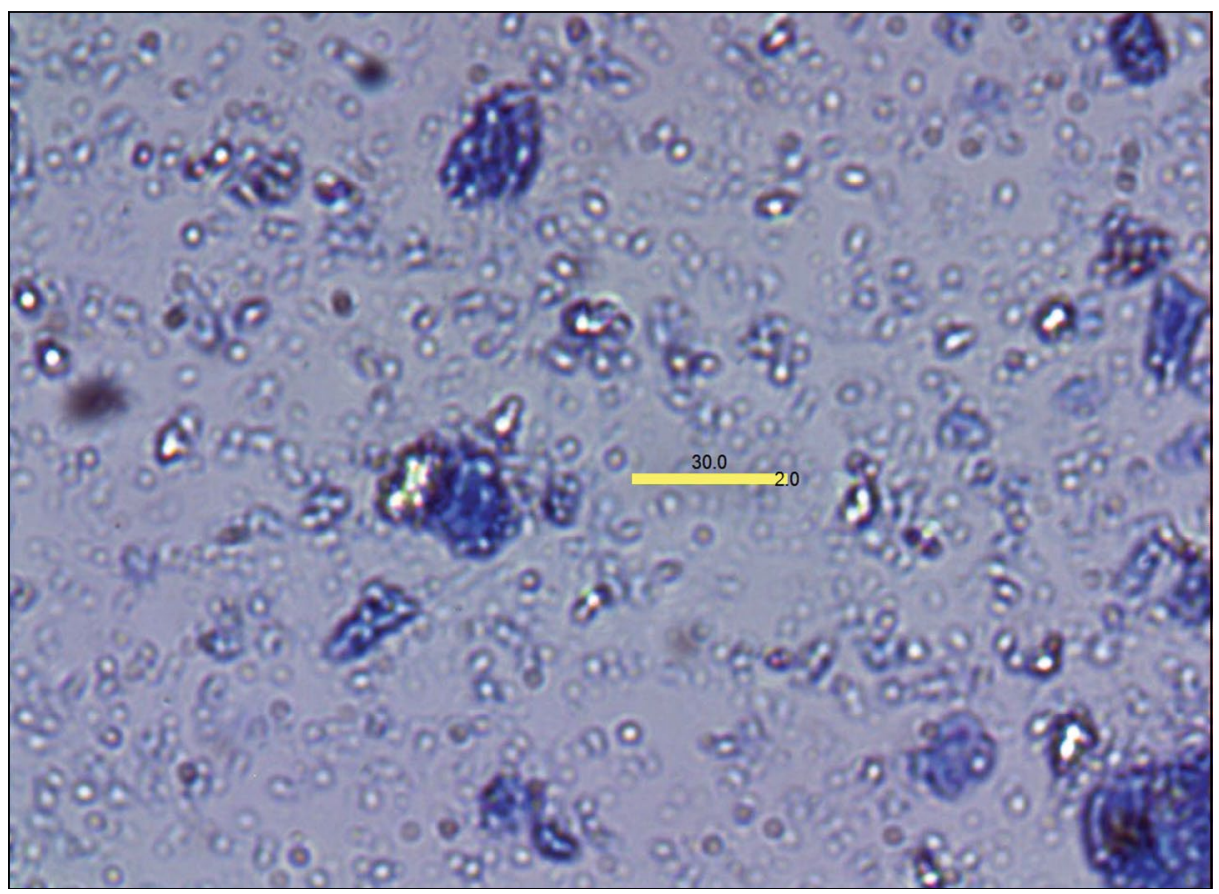

Photograph 17 Western Cape yellow kaolinitic soil after addition of methylene blue following treatment with dispersant and mechanical stirring to the specification of SANS 3001 GR3

Almost all of the particles are about 2 microns or slightly larger. Many form groups of from a few to many particles. Many appear to be properly dispersed, but many are not.

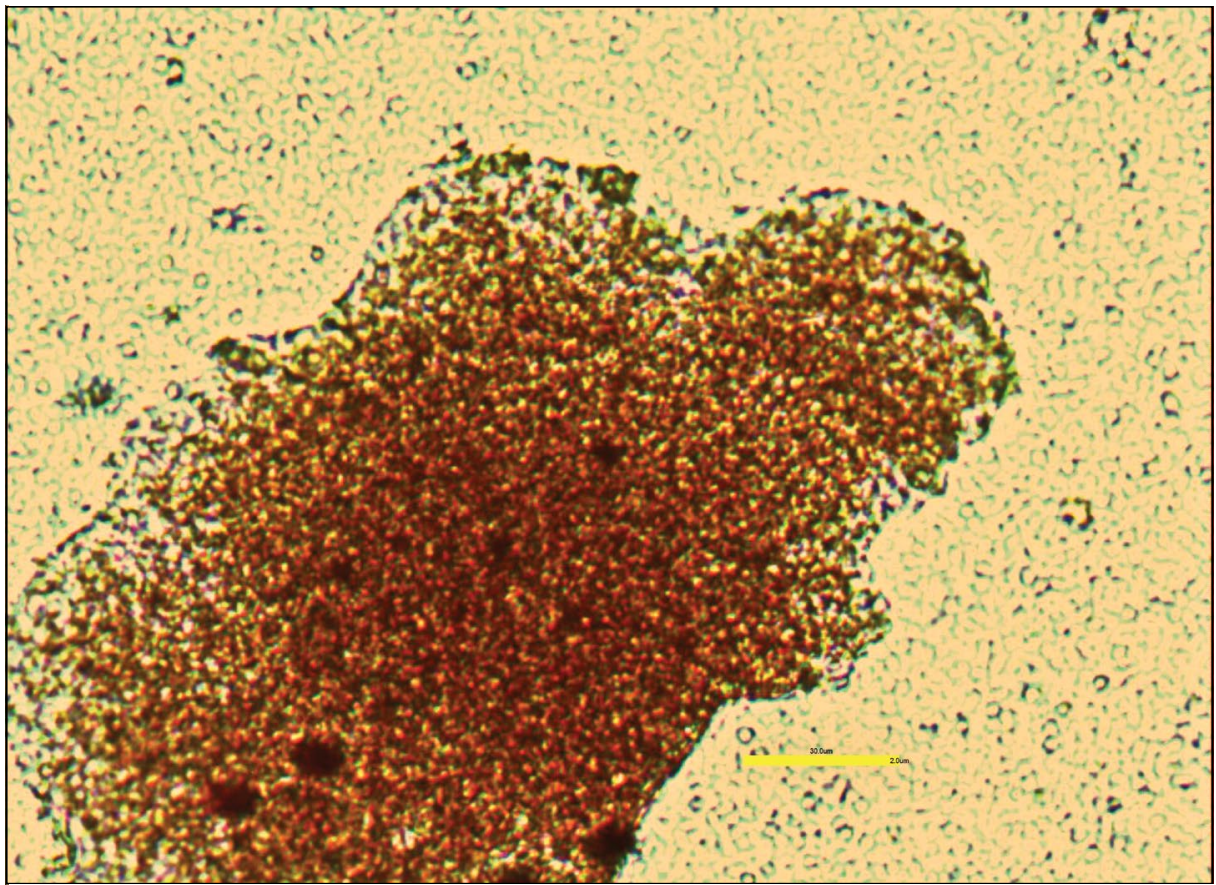

Photograph 18 Dark-brown sandy clay from a road project at Thaba Nchu in the central Free State after preparation for hydrometer analysis by soaking in dispersant and mechanical agitation according to SANS 3001 GR3

This sand grain is of the order of 200 microns long and 100 microns wide. It appears to be completely covered with clay-size particles. Many clay particles around it are dispersed, although most are out of focus and cannot be clearly seen.

of clay remaining attached to larger particles or forming agglomerations with other clay particles.

In some cases the lack of dispersion was fairly small, but in some cases a substantial fraction of the clay particles appeared to be undispersed. This suggests that it will not be reasonable to look for some universal factor by which hydrometer results could be corrected. It appears that predictions based on clay fraction determined by the procedure of SANS 3001 GR3 may be very unreliable for some soils. Since the SANS 3001 procedure is quite similar to that of many other countries, it is likely that this problem may be widespread. The samples prepared at the UFS Soil Science Laboratory, using soil science procedures with some differences to those of SANS 3001 GR3, showed visibly similar results to those prepared at the CUT laboratory using the GR3 procedure.

It might be reasonable to consider specifying different de-flocculants for different types of soil. Rodriguez et al (2011) found that lithium hydroxide is very efficient for high-CEC soils, but is not effective for dispersing lowCEC electropositive soils. Rolfe et al (1960) found considerable difference in the clay yield given by a number of dispersants across different types of clay in hydrometer tests. Perhaps it is not surprising that the single dispersant specified for all South African soils appears to be reasonably adequate for some soils and completely inadequate for others. Changing dispersant may be futile, however, since most of the soils tested showed mixtures of clay ranging from small, high CEC particles (much of it probably montmorillonite) to large, low CEC particles (much of it probably kaolinite). If a dispersant is not efficient for several types of clay, it will not give reliable results for these soils.

The methods of quantitatively assessing the efficiency of de-flocculants for geotechnical and soil-science purposes (Rodriguez et al 2011; Rolfe et al 1960) take hydrometer yield as the standard of comparison. There appears to have been no attempt to assess how much of the clay remains undispersed. The use of even the most efficient dispersant for any particular clay may therefore give poor results.

There is also the question of mechanical agitation. Rodriguez et al (2011) noted that horizontal mechanical shaking in helicoidal motion, with the addition of coarse sand as an abrasive, is more effective for dispersion than the conventional method. They did note, however, that its efficiency is not the same for all soils.

\section{CONCLUSION}

It appears that Savage's suspicion that "deflocculation of many clays is seldom fully completed at the time of testing" is well founded. None of the clays tested reached good dispersion, even when all aspects of the dispersion procedure were extended substantially. Clay coating of large (silt/sand) particles was observed to some extent in all samples which contained silt and sand particles - in some cases to a very considerable extent. Such particles will probably settle at the rate of silt/sand particles and their clay coating will not be assessed with the clay fraction.

It may be advisable to consider the hydrometer unreliable for any critical 
analysis such as heave prediction. Work in progress at the CUT soil mechanics research group is attempting to find more reliable methods of assessing clay fraction, but this is at a very early stage and is therefore unlikely to be able to give reliable quantitative results for at least two years. The quest for better methods of assessing clay content should perhaps become a priority on a wider scale.

\section{ACKNOWLEDGEMENTS}

The authors wish to express their thanks and appreciation to Prof L van Rensburg and Mrs Y Dessels of the Free State University, and Prof SW Jacobsz of the University of Pretoria, for their assistance and encouragement, as well as the National Research Foundation (NRF) for its financial support of the CUT soil mechanics research group's work.

\section{REFERENCES}

Al-Lami, H S 2008. Evaluation of some water-soluble dispersants for different types of kaolin powders. Al-Taqani, 21: 95-100. Available at: http://www.iasj. net.

Bühmann, C \& Kirsten W F A 1991. The mineralogy of five weathering profiles, developed from Archaean granite in the eastern Transvaal, Republic of South
Africa. South African Journal of Plant and Soil, 3: 126-152. DOI: 10.1080/02571862.1991.10634823.

Das, B M 2008. Advanced Soil Mechanics, 3rd ed. New York: Taylor and Francis.

Konert, M \& Vandenberghe, J 1997. Comparison of laser grain size analysis with pipette and sieve analysis: A solution for the underestimation of the clay fraction. Sedimentology, 44(3): 523-535.

Ma, Z, Merkus, H G, de Smet, J G A E, Heffels, C \& Scarlett, B 2000. New developments in particle characterization by laser diffraction: Size and shape. Powder Technology, 111(1-2): 66-78.

McCave, I N, Bryant, R J, Cook, H F \& Coughanowr, C A 1986. Evaluation of a laser-diffraction-size analyser for use with natural sediments. Journal of Sedimentary Petrology, 56(4): 561-564.

Mishra, A K, Ridlo, M O \& Higashi, T 2011. Comparison of the clay fraction of Ariake clay determined by Japanese and ASTM standards. Marine Georesources and Geotechnology, 29(2): 110-116. DOI: 10.1080/1064119X.2012.525138. 29:110-116, 2011.

Nettleship, I, Cisko, L \& Vallejo, L E 1997. Aggregation of clay in the hydrometer test. Canadian Geotechnical Journal, 34: 621-626.

Robinet, J C, Coelho, D \& Altmann, S 2011. State of the art on cation diffusion in clay mineral systems. Karlsruhe, Germany: European Commission (Community Research), CatClay Report 1/5/2011. Rodrigues, C, de Oliveira, V A, da Silveira, P M \& Santos, G G 2011. Chemical dispersants and pretreatments to determine clay in soils with different mineralogy. Journal of the Brazilian Society of Soil Science, 35(5): 1589-1596. Available at: http://www. redalyc.org.

Rolfe, B N, Miller, R F \& McQueen, I S 1960. Dispersion characteristics of montmorillonite, kaolinite, and illite clays in waters of varying quality, and their control with phosphate dispersants. Washington DC: Geological Survey and Colorado State University, Professional Paper 334-G.

SANS (South African National Standard) 2011. SANS 3001: 2011, Edition 1.1. Civil Engineering Test Methods, Part GR3. Pretoria: SABS Standards Division.

Savage, P F 2007. Evaluation of possible swelling potential of soil. Proceedings, 26th South African Transport Conference (SATC 2007), Pretoria, 9-12 July 2007.

Skempton, A W 1953. The colloidal "activity" of clays. Proceedings, 3rd International Conference on Soil Mechanics, Zurich, 1, pp 57-60.

Turoz, M \& Tosun, H 2011. The use of methylene blue test for predicting swell parameters of natural clay soils. Scientific Research and Essays, 8: 1780-1792.

Van der Merwe, D H 1964. The prediction of heave from the plasticity index and percentage clay fraction in soils. The Civil Engineer in South Africa, June: $103-107$.

Zschimmer \& Schwarz GmbH \& Co 2014. Mechanisms of action of deflocculates and dispersants in ceramic bodies. Ceramics. Available at: http://www. zschimmer-schwarz.com/en/simon/zschimmerschwarz/media/site/downloads/fachinfo/eng/ Fach/E_WirkmechVerfluess.pdf. 